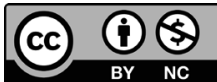

\title{
VÍCIOS E VIRTUDES NAS POLÍTICAS PÚBLICAS DE COTAS EDUCIONAIS: OS OBSTÁCULOS AO DESENVOLVIMENTO HUMANO COM A CHEGADA DOS COTISTAS NAS UNIVERSIDADES PÚBLICAS
}

VICES AND VIRTUES IN EDUCATIONAL POLICIES PUBLIC POLICIES: THE OBSTACLES TO HUMAN DEVELOPMENT WITH THE ARRIVAL OF THE STUDENTS IN THE PUBLIC UNIVERSITIES

Edson Mitsuo Tiujo

Bruno Grego dos Santos

\section{RESUMO}

O artigo se propõe a discutir as políticas públicas de cotas educacionais sob o crivo da justiça. Assumindo-se uma leitura liberal igualitária da vigente Constituição brasileira, a pesquisa debruça-se em analisar desde as virtudes das políticas de acesso e ingresso dos cotistas nas universidades públicas até os persistentes vícios (preconceito, racismo, intolerância e discriminação) nas relações entre cotistas e não cotistas, no ambiente universitário. Adotando-se o método hipotético-dedutivo, parte-se da premissa de que o consenso sobre o valor da igualdade ainda não está totalmente formado no meio social, embora já o esteja no âmbito constitucional brasileiro. Nesse sentido, a pesquisa propõe a necessidade da missão das universidades públicas estarem em conformidade com as políticas de continuidade e permanência dos estudantes, sob pena de os vícios presentes no meio social e insistentes nos ambientes universitários suplantarem as conquistas sociais e distributivas obtidas até então.

Palavras-chave: Vícios. Virtudes. Consenso. 


\section{ABSTRACT}

The article proposes to discuss the public policies of educational quotas under the sieve of justice. Assuming an egalitarian liberal reading of the current Brazilian Constitution, the research focuses on analyzing from the virtues of quota access and admission policies in public universities to the persistent vices (prejudice, racism, intolerance and discrimination) in relations between quota holders and non-quota students, in the university environment. Adopting the hypothetical-deductive method, it is assumed that the consensus on the value of equality is not yet fully formed in the social environment, although it is already in the Brazilian constitutional sphere. In this sense, the research proposes the need for the mission of public universities to be in conformity with the policies of continuity and permanence of students, under pain of the vices present in the social environment and insistent in the university environments to supplant the social and distributive conquests obtained until then

Keysword: Vices. Virtues. Consensus.

\section{INTRODUÇÃO}

0 artigo se propõe a discutir as políticas públicas de cotas educacionais sob o crivo da (in)justiça em aspectos diversos dos abordados até então nos mais variados trabalhos sobre o tema. Muitos estudos já foram dedicados às políticas de acesso de estudantes pertencentes a grupos minoritários em universidades públicas, mas poucos foram dedicados ao assunto dos vícios (preconceito, racismo, intolerância e discriminação) que surgem e persistem nos ambientes universitários, notadamente após a chegada dos beneficiados aos bancos escolares. Principalmente por modificarem o critério qualitativo de seleção e adotarem critérios alternativos para beneficiamento de determinados grupos minoritários, essas ações governamentais acabam dando ensejo a diversas discussões no âmbito da justiça.

A questão que se coloca em debate neste artigo é se as políticas de acesso às universidades públicas são suficientes para cumprir, com a justiça que se espera, as ações afirmativas educacionais. Quer-se com isso investigar se reações adversas aos grupos minoritários podem 
comprometer tais políticas sociais e distributivas, principalmente quanto ao fim a que se propõem.

A abordagem será feita por meio de uma leitura liberal igualitária da Constituição da República Federativa do Brasil de 1988 (CRFB), tendo por fundamento teóricos da justiça, como John Rawls, Alasdair MacIntyre, Agnes Heller, Ferenc Feher e Michael Sandel. A partir desses marcos teóricos, as noções de justiça ou injustiça serão relacionadas, ao longo do trabalho, com as noções de vícios e virtudes, assim compreendidas como os traços de caráter de bases amplas que não são desejados no convívio social ou, ao contrário, que as pessoas queiram encontrar umas nas outras.

Nessa linha de raciocínio, a pesquisa se debruça sobre três objetivos. 0 primeiro consiste em analisar as políticas de acesso e ingresso por cotas nas universidades públicas, destacando suas virtudes, especialmente quanto ao beneficiamento de diversos grupos de pessoas marginalizadas. 0 segundo traduz-se em discutir os persistentes vícios existentes nas relações entre cotistas e não cotistas, desvendando que tais percepções não são apenas intuitivas, mas presenciadas empiricamente de forma implícita e explícita nos ambientes universitários. 0 terceiro consiste em revelar os motivos que fazem persistir os preconceitos, racismos, intolerâncias e discriminações contra os beneficiários dessa política, indicando, por derradeiro, os rumos necessários para que tais vícios não suplantem as conquistas obtidas até então por referidas ações governamentais.

A pesquisa adota o método hipotético dedutivo, partindo da premissa de que as políticas de cotas educacionais - acesso e ingresso - passaram pelo crivo da justiça, independentemente da leitura (comunitária, republicana e liberal igualitária) que se faça do consenso constitucional, mas necessitam ser complementadas para que os vícios não persistam. Propõe-se, para tanto, o aperfeiçoamento das políticas de cotas educacionais, notadamente com a implementação de outras políticas, como as de permanência e continuidade dos cotistas nas universidades para que, assim, possa se atingir a plena finalidade da ação governamental. 


\section{AS POLÍTICAS PÚBLICAS DE INGRESSO POR COTAS NAS UNIVERSIDADES PÚBLICAS: UM ENFOQUE SOB O CRIVO DA (IN)JUSTIÇA}

A chamada política de cotas no ensino superior público visa à modificação dos critérios de seleção dos candidatos à matrícula inicial nas universidades públicas. A referida política de ação afirmativa, portanto, não cogita de um aumento no número de vagas nas universidades públicas, mas sim de um remanejamento (ou reserva) de uma determinada quantidade de vagas a um específico grupo de pessoas (RODRIGUES; RODRIGUES, SILVA; ALBUQUERQUE, 2015, p. 49), levando-se em consideração certos critérios predeterminados em lei e, também, em estatutos universitários.

No Brasil, as primeiras seleções por cotas ocorreram por meio da autonomia conferida às universidades públicas pela Lei n. 9.394/1996 (Lei de Diretrizes e Bases da Educação), sendo reputado à Universidade do Estado do Rio de Janeiro (UERJ), o pioneirismo na criação do sistema de cotas em vestibulares para cursos de graduação (MAIA; MELO, 2017, p. 171). A política de cotas também já foi discutida judicialmente, no Recurso Extraordinário (em Mandado de Segurança) n. 597.285/ RS, contra a Universidade Federal do Rio Grande do Sul (UFRS), e na Arguição de Descumprimento de Preceito Fundamental n. 186, sendo reconhecido pelo Supremo Tribunal Federal (STF), em ambos os casos, a sua constitucionalidade. Por último, após profundas discussões, foi editada a Lei n. 12.711/2012, com o intuito de implantar o sistema de reserva de vagas nas universidades e instituições públicas federais, para estudantes oriundos das escolas públicas, de baixa renda, não brancos, de origem indígena e deficientes físicos.

A ação afirmativa para remanejamento de vagas modificou parcialmente o critério de seleção adotado até então pelas universidades públicas, qual seja a avaliação meritocrática, ou seja, pela capacidade individual de cada estudante, segundo a qual o candidato que obtiver o melhor desempenho por notas nos testes aplicados terá direito de ingresso na faculdade pública escolhida.

Diversamente do critério vigente até então, a política pública de cotas, nos moldes em que foi implementada no Brasil, por meio da Lei 
n. 12.711/2012, modificou parcialmente o critério qualitativo de seleção e adotou critérios alternativos para beneficiamento de determinados grupos minoritários, sendo, portanto, de natureza social e distributiva. É de cunho social, haja vista que objetiva primordialmente corrigir problemas sociais diversos e, na medida do possível, ampliar o bemestar dos cidadãos (arts. 3ํ e 5o da Constituição da República). Na mesma linha, são também políticas distributivas, uma vez que "são orientadas para o conflito e polarização, desviando e deslocando conscientemente recursos financeiros, direitos e valores de uma camada social ou grupo da sociedade em detrimento da outra" (FREY, 2000, p. 224).

Atualmente, no Brasil, diversos critérios têm sido adotados para a seleção dos estudantes, sendo os mais comuns, o étnico-racial ${ }^{1}$ e o social-econômico ${ }^{2}$. Ademais, inúmeros outros grupos de pessoas, além de pobres e não brancos, por critérios distintos, têm sido beneficiadas por tais ações governamentais, como ocorreu mais recentemente com os transexuais, travestis, quilombolas, ciganos, pessoas com deficiência, autismo e altas habilidades ${ }^{3}$.

Evidentemente, as referidas políticas públicas não passaram imunes a críticas, notadamente, por parte das pessoas pertencentes aos grupos majoritários, sendo corriqueiramente questionadas sob o crivo da justiça. Por esse motivo, a primeira questão que se coloca é saber: as políticas de cotas educacionais são justas?

Inicialmente, é importante destacar que a pesquisa não distingue os diversos critérios de reserva de vagas, embora a distinção seja bastante pertinente, uma vez que cada critério dá ensejo a uma ação afirmativa diversa, com beneficiários e objetivos distintos. Nesse sentido, é indiscutível que as cotas étnico-raciais e social-econômicas não se confundem e possuem graus de aceitabilidade e rejeição diferentes, mas a pesquisa as tratará como uma única política pública em favor de grupos minoritários. A justificativa para isso é que o objetivo principal da pesquisa consiste em verificar eventuais vícios ${ }^{4}$ nas referidas políticas públicas com a chegada dos cotistas nas universidades públicas, questão essa que será enfrentada nos próximos tópicos.

Retornando a pergunta, convém, agora e inicialmente, debruçar sobre a questão da justiça das políticas públicas de cotas educacionais. Como 
já se disse anteriormente, as referidas ações afirmativas são de natureza social e distributiva. Nesse sentido, as investigações que se propõe a fazer são: (a) encontrar, no ordenamento jurídico brasileiro, o fundamento para a justiça social e distributiva e, a partir daí, (b) o fundamento filosófico que legitimou os legisladores, constituinte e constituído, a adotar tais políticas públicas em favor de grupos minoritários e, em contrapartida, em desfavor de grupos majoritários.

Para tanto, propõe-se a realização dessa investigação, promovendose uma regressão que se inicia com a procura dos valores constitucionais que informaram as políticas públicas de reserva de vagas até se chegar aos fundamentos filosóficos que informaram, por sua vez, os valores constitucionais da Lei Maior brasileira. Ao final dessa investigação buscase encontrar a virtude da justiça nessas ações governamentais.

0 conteúdo da Constituição de um país e de quaisquer legislações que nele vigore deve ser virtuosa, no sentido de permitir a melhor convivência possível para a comunidade de pessoas. Virtudes, como explicam Agnes Heller e Ferenc Feher (2002, p. 117), são traços de caráter tidos como exemplares por uma comunidade de pessoas e são adquiridos pela prática. Ou ainda, nas palavras de Alasdair MacIntyre (2001, p. 409), virtude "é uma disposição ou sentimento que produz em nós obediência a certas normas" legais ou sociais.

A primeira virtude da vida política, portanto, é a justiça. Uma comunidade sem uma concepção de justiça carece de base para a comunidade política. A falta de base para a comunidade política, por sua vez, pode ameaçar a própria sociedade. Nesse sentido, Geiziele Jensen, reescrevendo de modo mais compreensível John Rawls, explica que "a justiça deve figurar como a virtude primeira de uma sociedade, devendo ser vislumbrada num plano institucional, posto que são as instituições que podem beneficiar ou prejudicar uma parcela da sociedade" (JENSEN, 2015, p. 57).

As instâncias administrativas e legislativas, ao elaborarem as políticas públicas de cotas, assim o fizeram tendo por fundamento a CRFB de 1988. Essa Constituição, por sua vez, implantou no Brasil, o chamado Estado Social, caracterizado principalmente por garantir direitos fundamentais, individuais e sociais, aos seus cidadãos. Muitos desses 
direitos fundamentais, especialmente os sociais, por envolverem conflitos de direitos e interesses de grupos, como é o caso da reserva de vagas, acabam dando ensejo a diversas discussões no âmbito da justiça.

Para tanto, é preciso encontrar o valor que se atrela à virtude da justiça no texto constitucional. Nesse sentido, recorre-se novamente a Agnes Heller e Ferenc Féher, segundo os quais "as virtudes estão relacionadas a valores" e "os valores são bens" (HELLER; FÉHER, 2002, p. 118). Assim, qual é o bem (valor) tutelado pela CRFB de 1988 e que dá fundamento às políticas públicas de reserva de vagas? Esse valor seria a igualdade.

$\mathrm{Na}$ CRFB, portanto, a virtude da justiça é o valor da igualdade. Nesse sentido, expressa-se Clèmerson Merlin Clève (2015, p. 673), ao sustentar que existe na Constituição uma reserva de justiça, cujo núcleo duro aponta para a igualdade, inclusive fática, afigurando-se simultaneamente como um direito, princípio e objetivo, enquanto critério para a escolha da justiça das posições sociais. Ademais, ainda transcrevendo a fala do constitucionalista, tem-se que a conexão entre justiça e igualdade deve estar presente desde o momento da construção normativa e institucional até o de aplicação do direito. Para arrematar sua profícua reflexão, diz o constitucionalista que, a igualdade é um ideal a ser alcançado e está implícito em toda e qualquer concepção plausível de justiça; a sociedade somente será justa quando considera os cidadãos iguais e, isso, exige instituições e normas que promovam a igualdade factual, com políticas sociais de igualação.

A igualdade, portanto, é o valor que informa a elaboração das ações afirmativas para a reserva de vagas. Ou seja, é a partir da leitura de justiça que se extrai da CRFB que se permite a elaboração de políticas públicas dessa natureza (social e distributiva).

Mas a adoção do valor da igualdade para a virtude da justiça seria o valor correto? A resposta, para tanto, depende da leitura (filosófica) que se faz da Constituição. Nesse particular, mais uma vez apoiando-se em Clèmerson Merlin Clève ${ }^{5}$, a reserva de justiça condensada na Constituição autoriza várias leituras (comunitária, republicana e liberal igualitária), concentrando um núcleo material compartilhado pelas mais importantes teorias da justiça; e, igualmente, repele outras (libertária, anárquica, perfeccionista ou comunista). 
Para explicar os valores constitucionais adotados pela CRFB de 1988 e as consequentes políticas públicas sociais e distributivas recorre-se a uma leitura liberal igualitária, tendo por fundamento importantes teóricos da justiça, como John Rawls, Michael Sandel, Agnes Heller, Ferenc Feher e Roberto Gargarela.

De início, para explicar os fundamentos filosóficos das políticas públicas de cotas educacionais, invoca-se alguns elementos de "Uma Teoria da Justiça" (2016) e "Justiça como Equidade" (2003) de John Rawls, como os princípios da justiça, o princípio da diferença e o mérito moral. Os primeiros - princípio da justiça - justificam a escolha do valor da igualdade como a virtude da justiça. 0 princípio da diferença, por conseguinte, explica a discriminação positiva promovida pelas ações afirmativas em favor de grupos minoritários. Por último, a ideia do mérito moral é invocada não para rechaçar totalmente o critério meritocrático como o único critério de seleção nos concursos vestibulares, mas para impor a necessidade da adoção de critérios alternativos.

De forma bastante breve, os princípios da justiça são aqueles escolhidos pelas pessoas na chamada posição original, ou seja, no status quo inicial apropriado para assegurar que os consensos básicos nele estabelecidos sejam equitativos (RAWLS, 2016, p. 16). Nessa situação inicial, as pessoas, por meio de um acordo hipotético, escolheriam os princípios orientadores da sociedade. 0 grande lance da posição originária e do acordo hipotético são que a eleição dos princípios da justiça seria feita sob o véu da ignorância, assim compreendido como o estágio em que as pessoas agem com maior imparcialidade, pois são isentas de objetivos e interesses próprios (RAWLS, 2016, p. 153). Nas palavras de Clémerson Merlin Clève, nessa situação de ignorância, as pessoas "desconhecem a posição futura na qual residirão e também quais bens e princípios seriam disputados no meio social" (2015, p. 674).

Nesse contexto, para Michael Sandel, a Teoria de John Rawls sustentase na equidade, haja vista que "o véu da ignorância garante a equanimidade do poder e do conhecimento que a posição original requer" (2012, p. 188). Dessa forma, continua o raciocínio, ao ignorar sua posição na sociedade, suas forças e fraquezas, seus valores e objetivos, as pessoas sob o véu da 
ignorância não podem valer-se de vantagens umas em relação às outras, ainda que involuntariamente, valendo-se de uma posição de barganha.

Diante disso, os princípios de justiça escolhidos pelas pessoas sob o véu da ignorância, com base na Teoria da Justiça de John Rawls, seriam: (i) "cada pessoa deve ter um direito igual ao mais abrangente sistema de liberdades básicas iguais que seja compatível com um sistema semelhante de liberdades para as outras" (2016, p. 73); e, (ii) "as desigualdades sociais e econômicas devem ser ordenadas de tal modo que sejam ao mesmo tempo (a) consideradas como vantajosas para todos dentro dos limites do razoável (princípio da diferença), e, (b) vinculada a posições e cargos acessíveis a todos" (2016, p. 73). Em síntese, Michael Sandel (2012, p. 179), amparado em John Rawls, enumera como os princípios eleitos o das liberdades básicas para todos os cidadãos e da equidade social e econômica (princípio da diferença).

Esses princípios, por sua vez, incorporar-se-iam à sociedade, sendo compartilhados por todos os seus integrantes ${ }^{6}$, afigurando-se como modus vivendi de uma comunidade até serem ratificados e constituírem-se como consenso constitucional e, ao final, como consenso sobreposto. 0 consenso sobreposto é outro elemento da Teoria de John Rawls e significa que os princípios políticos não devem favorecer nenhuma das concepções de bem que são motivo de desacordo entre membros de uma sociedade, de modo que "o essencial é que haja um objetivo final partilhado, e modos aceitos para promovê-los, que permitam o reconhecimento público das realizações de cada um" (RAWLS, 2016, p. 586). Como explica Roberto Gargarela, o consenso sobreposto refere-se a um acordo entre pessoas razoáveis que só aceitam doutrinas abrangentes razoáveis. Significa dizer que, "aparece como única forma de permitir que, em um contesto pluralista cada indivíduo chegue a aderir à concepção pública da justiça: esse consenso só pode ser alcançado uma vez que a concepção pública em questão apareça como razoável ou mesmo como verdadeira aos olhos de todos" (2008, p. 231). Nesse estágio, explica Gisele Cittadino (1999, p. 104), o consenso mútuo modela a dimensão moral da cultura pública, lhe dá estabilidade e legitimidade e, ainda, define um dever cívico que se impõe aos cidadãos em uma sociedade democrática liberal. 
Outro elemento da Teoria da Justiça de John Rawls e importante para fundamentar as políticas públicas sociais e distributivas, especialmente de reserva de vagas, é o princípio da diferença. Esse princípio é enumerado por John Rawls como um dos princípios da justiça, isto é, como um daqueles princípios que seriam escolhidos pelas pessoas na posição original e sob o véu da ignorância, que permitiriam o maior benefício para os menos favorecidos (RAWLS, 2016, p. 267).

Clèmerson Merlin Clève (2015, p. 674), reexplicando John Rawls, afirma que o princípio da diferença é um postulado para correção das desigualdades naturais. Por esse princípio, "as desigualdades sociais e econômicas só podem ser toleradas caso promovam o benefício dos que ocupam as posições menos vantajosas dentro da comunidade" (CLÈVE, 2015, p. 674). Isso deve ser assim, porque, na prática, nem todas as pessoas nascem com as mesmas habilidades e podem ser sustentadas por uma família abastada. Por isso, diz Michael Sandel (2012, p. 191), "permitir que todos participem da corrida é uma coisa boa, mas se os corredores começarem de pontos de partida diferentes, dificilmente será uma corrida justa".

Nesse sentido, o princípio da diferença justifica perfeitamente a implementação de políticas públicas para compensar ou assistir grupos minoritários, "adotando meios para que todos os membros de uma determinada comunidade possam, ao menos, ter a mesma situação para o desenvolvimento de suas habilidades" (CLÈVE, 2015, p. 674), implicando isso em semelhante ponto de partida para todos.

Por último, ainda pertinente a Teoria da Justiça de John Rawls, convém tecer comentários em relação à injustiça ou arbitrariedade do mérito moral, como forma de alternar a adoção dos critérios de admissão nos concursos vestibulares, rechaçando a adoção exclusiva do critério qualitativo (meritocrático).

Para John Rawls (2016, p. 108), a distribuição dos talentos naturais (inteligência, beleza, força, altura, entre outros) e de pontos de partida mais favoráveis (como, a maior riqueza, renda, oportunidade e poder em decorrência do nascimento) não possuem qualquer relação com a justiça ou injustiça. Isso porque, ainda que, no curso da vida essas pessoas se mostrem mais esforçadas do que as outras e, consequentemente, 
merecedoras das suas vitórias, é certo que esta característica pessoal (esforço) é influenciada por aquelas contingências (talentos naturais e circunstâncias familiares), cujos créditos não se pode reivindicar ${ }^{7}$.

Por esse motivo, explica Michael Sandel (2012, p. 198), existe arbitrariedade (injustiça) moral nas aptidões naturais e inatas e, por isso, a justiça distributiva não é questão de premiar o mérito moral. Por isso que, a adoção do critério meritocrático para seleção nos concursos vestibulares é questionada do ponto de vista da justiça, pois os aprovados são recompensados por suas aptidões naturais e contingências familiares, tendo, assim, direito à vaga na faculdade não por justiça, mas por expectativa legítima.

Evidentemente, contudo, que as aptidões naturais e contingências familiares não podem ser ignoradas. Por isso, teoriza John Rawls (2016, p. 108), compete à estrutura básica da sociedade saber ordenar essas diferenças, de modo que as contingências trabalhem para o bem dos menos favorecidos. É preciso montar o sistema social e político, de modo que ninguém ganhe ou perca em razão dos bens naturais distribuídos arbitrariamente ou à posição inicial que ocupa na sociedade em virtude do seu nascimento.

Clèmerson Merlin Clève (2015, p. 674) explica, com base na teoria de John Rawls, que a avaliação da justiça ou injustiça da sociedade decorre da forma como as instituições lidam com os fatos naturais. As instituições, complementa Geiziele Jensen (2015, p. 56), devem, assim, compensar de alguma forma as desigualdades imerecidas e decorrentes desses diversos fatores naturais e contingenciais. Por isso, continua a autora, é que o princípio da diferença elaborado por John Rawls tem tamanha sustentação, haja vista que trata as desigualdades como justificáveis, desde que, "as instituições promovam uma ordenação que dê atenção àqueles com menos dotes inatos e aos oriundos de posições sociais menos favoráveis, a fim de tratar as pessoas igualitariamente" (JENSEN, 2015, p. 56).

Pelos fundamentos expostos, constata-se que a política de acesso / ingresso às universidades por critérios alternativos (social-econômico, étnico-racial e de gênero) de beneficiamento a grupos minoritários passou pelo crivo da justiça, notadamente pela concepção desenvolvida pelos liberais igualitários. Tanto o é verdade que, aparentemente a 
questão do sistema de cotas atingiu um consenso por parte dos Poderes Públicos: (a) político, mediante a elaboração da Lei n. 12.711/2012 pelas instâncias administrativa e legislativa; e o (b) judicial, mediante o julgamento da constitucionalidade da ação governamental de reserva de vagas na Arguição de Descumprimento de Preceito Fundamental n. 186 e do Recurso Extraordinário (em Mandado de Segurança) n. 597.285/RS.

Partindo desse ponto, ou seja, de que as políticas de cotas educacionais são justas, a questão se coloca a partir de agora, diz respeito a continuidade da ação governamental e a permanência dos cotistas nas universidades públicas. Com enfoque nas representações sociais constatadas na relação entre cotistas e não cotistas e os vícios (externalidades negativas) decorrentes da ação afirmativa, pretende-se verificar, nos próximos tópicos, se as políticas de reserva de vagas já se constituíram em acordo compartilhado pela sociedade. A hipótese do trabalho é para uma resposta negativa. Em vista disso, com base na própria teoria liberal igualitária, objetiva-se analisar por que o consenso do sistema de cotas ainda não aconteceu no meio social em geral. Por último, o trabalho se propõe a discutir se tais vícios (externalidades negativas) influenciam, direta e negativamente, a justiça das políticas públicas de cotas e as conquistas obtidas até então.

\section{AS REPRESENTAÇÕES SOCIAIS NOS AMBIENTES UNIVERSITÁRIOS COM A CHEGADA DOS ESTUDANTES COTISTAS: A PERSISTÊNCIA DOS VÍCIOS DO PRECONCEITO, DO RACISMO, DA INTOLERÂNCIA E DA DISCRIMINAÇÃO}

Apesar da justiça das políticas públicas de reserva de vagas, constatada com base nos fundamentos liberais igualitários acima expostos, as representações sociais no ambiente universitário com a chegada dos estudantes cotistas apontam para a existência de vícios na relação entre estes e os estudantes não cotistas, como o preconceito, o racismo, a intolerância e a discriminação. 
Como a implantação do sistema de cotas educacionais é bastante recente e o programa ainda está em fase de implementação, com previsão de avaliação e revisão para o ano de $2022^{8}$, as percepções feitas até o momento limitam-se apenas a quantificar os estudantes nas universidades públicas, bem como a qualificar os seus desempenhos e rendimentos ${ }^{9}$.

Em contrapartida, no que se refere às relações entre cotistas e não cotistas e a inclusão social daqueles, por meio de ações para reconhecimento e pertencimento ao grupo, pouco se tem pesquisado. Aliás, nem mesmo as políticas de permanência e continuidade têm recebido seguimento por parte dos Poderes Públicos, embora, por vezes, tenham sido divulgadas por legisladores, administradores, gestores de universidades e até mesmo por doutrinadores, com os objetivos de propiciar simultaneamente o acesso e a permanência dos estudantes nas universidades públicas.

Principalmente, porque as políticas de cotas educacionais tenham por fundamento a justiça distributiva e visem ao combate das desigualdades entre as pessoas, as reações adversas aos grupos minoritários (beneficiados) são intuitivamente previsíveis e empiricamente demonstráveis. Quanto maior o número de pessoas beneficiadas por características diversas como transexuais, travestis, quilombolas, ciganos, pessoas com deficiência, autismo e altas habilidades -, maiores são as tendências aos preconceitos e às discriminações odiosas.

Juristas e filósofos já intuíram e previram as consequências negativas de uma política de grupos. Roberto Gargarela, por exemplo, afirma expressamente que "um sistema de cotas parece mais reforçar e encorajar a divisão da sociedade em grupos diferentes e separados entre si que favorecer a melhor integração de todos esses grupos" (GARGARELA, 2008, p. 177). Para ele, esse tipo de política ocasiona o incremento das rivalidades e preconceitos entre os grupos até provocar o constrangimento nos próprios indivíduos favorecidos, incutindo-lhes a consideração de que esse tipo de programa de ação afirmativa é degradante para o seu próprio grupo (GARGARELA, 2008, p. 177-8).

Alasdair MacIntyre (2001, p. 410-11) também relata sobre a dificuldade de implementação de acordos prévios por causa da cultura individualista, o que se agrava, ainda mais, nos casos envolvendo a justiça. Para contextualizar, cita exemplos de dois possíveis eleitores propostos por 
Robert Nozick e John Rawls, cada um com seus ideais políticos. 0 primeiro defende o direito de posse aos bens que adquiriu por esforço próprio, e que ninguém mais tem o direito de lhe tirar o que ganhou legalmente. O segundo, por sua vez, defende o princípio da distribuição e considera que toda desigualdade somente é justificada para melhorar as condições de vida dos pobres e dos desprivilegiados (MACINTYRE, 2001, p. 411).

Com isso, Alasdair MacIntyre (2001, p. 411) pretende dizer que, desde que a política para uma determinada pessoa não interfira na esfera de direitos ou interesses de outra, as partes não precisam discordar, aliás, podem até mesmo escolher as mesmas políticas e os mesmos políticos. Mas, a partir do momento em que as circunstâncias sejam tais que seja preciso sacrificar os projetos de um em detrimento do outro, torna-se claro que as pessoas passam a ter opiniões incompatíveis entre si acerca da justiça, reconhecendo como injustas ações afirmativas como a política de cotas.

Agnes Heller e Ferenc Feher (2002, p. 173), por sua vez, partem da ideia de que o direito é força. A justiça que decorre do direito, por conseguinte, seria definido de acordo com as necessidades e interesses que motivam conflitos em torno de afirmações de justiça. É que, "cada um e todos os grupos sociais seguem seu próprio interesse e chamam de justiça o que melhor convém a esse interesse" (HELLER; FÉHER, 2002, p. 173). Assim, quanto mais forte o grupo, mais os interesses desse determinado grupo coincidem com o que é tido como justo. Isso justifica a dificuldade de aceitabilidade dos benefícios concedidos por meio das cotas, reforçando a disputa entre os grupos.

Os vícios na relação entre cotistas e não cotistas presenciados nas representações sociais do ambiente universitário, no entanto, não ficam apenas no campo da intuição e da previsibilidade. Apesar dos poucos estudos feitos até o momento, como os abaixo mencionados, comprovou-se efetivamente que preconceitos, racismos, intolerâncias e discriminações estão realmente presentes nos campi das universidades públicas.

A relação entre cotistas e não cotistas foi tema da tese de doutorado da professora Maria Cristina Figueiredo Aguiar Guasti da Universidade Federal do Espírito Santo (Ufes), que resultou no livro "Representações Sociais: sobre as ações afirmativas no ensino superior e sobre os estudantes 
cotistas da Ufes". Segundo a pesquisa realizada, a professora verificou que a aceitação das cotas ainda é baixa, especialmente naqueles cursos com maior status, como Medicina, Engenharia, Arquitetura, Odontologia e Direito, e constatou a presença de rivalidade, preconceito e racismo como representações sociais contra os cotistas.

Ainda com base na pesquisa da professora capixaba, a questão social no campus da Universidade Federal do Espírito Santo (Ufes) mostrou que há divergência na forma como o estudante cotista é visto pelos estudantes não cotistas. Em primeiro lugar, o trabalho constatou a rivalidade entre os grupos. Os estudantes não cotistas, que em sua maioria são de origem escolar privada e classe social mais alta, percebem a política de cotas como uma forma de subtração de vagas de outros "amigos" pertencentes ao mesmo grupo e que, nas suas visões, tinham mais merecimento (GUASTI, 2016, p. 86). Em segundo lugar, a pesquisa observou que a representação social que os estudantes não cotistas fazem em relação aos cotistas, é que estes não têm um poder e um saber fazer, ou seja, não têm capacidade para estar na universidade, quer seja pelo rendimento, quer seja pela dificuldade financeira (GUASTI, 2016, p. 96). Em terceiro lugar, a pesquisa apurou também a existência de racismo e exclusão. E isso se evidencia, na medida em que os próprios estudantes não brancos revelam o desejo de não serem reconhecidos como cotistas, em função da cor de sua pele, para evitarem a exposição e a comparação. A política de cotas, enfim, não é vista como um direito nem pelos não cotistas que a encaram como um "roubo" e nem mesmo pelos próprios cotistas, que a enxergam apenas como um privilégio e uma oportunidade (GUASTI, 2016, p. 110).

Em outra pesquisa realizada por pesquisadores da Universidade de Brasília (UnB), da Universidade Estadual de Goiás (UEG) e do Centro Universitário de Brasília (Uniceub), também se evidenciou preconceito e discriminação contra os estudantes cotistas nos ambientes universitários. O que chamou a atenção na pesquisa, no entanto, foi o uso de medida indireta ${ }^{10}$ para avaliar as dimensões do preconceito, as quais intitularam de "modelo de discriminação justificada". A partir desse instrumento de medida indireta, os pesquisadores constataram que o preconceito e a discriminação vêm ocorrendo atualmente de forma velada e implícita. 
Segundo os pesquisadores, "em função de normas sociais igualitárias atuais, o preconceito tem assumido novas formas, ocorrendo uma mudança de um preconceito flagrante para formas mais sutis e escamoteadas de preconceito" (MODESTO; MINELLI; FERNANDES; RODRIGUES; BUFOLO; BITENCOURT; PILATI, 2017, p. 2), notadamente de forma impregnada e implícita. A discriminação, por sua vez, como comportamento contranormativo que é, tem-se mostrado não de modo descarado, mas por meio de mitos legitimadores que sirvam como justificativas, tornando-a mais aceita socialmente. Ou seja, o indivíduo ao praticar atos discriminatórios, apresenta justificativas (não preconceituosas) que pareçam legítimas e defensáveis em determinado contexto social (MODESTO; MINELLI; FERNANDES; RODRIGUES; BUFOLO; BITENCOURT; PILATI, 2017, p. 2).

Em síntese, a pesquisa conclui que, em um contexto como o brasileiro, em que prevalecem normas antipreconceito (Lei de Cotas), estudantes não cotistas tendem a se manifestar diretamente favoráveis a aceitação dos estudantes pertencentes aos grupos minoritários. Contudo, a partir do momento em que se lhes apresentam mitos legitimadores, como a inconstitucionalidade do sistema de reserva de vagas por violação ao princípio da igualdade, a insuficiência da política de cotas para resolver o problema da exclusão social ou a diminuição da qualidade do ensino na universidade, o preconceito tende a se revelar e a discriminação tende a ocorrer.

A conclusão a que se chega, portanto, é que "em circunstâncias que podem ser apresentadas justificativas que rompam com as normas antipreconceitos (Lei de Cotas), pessoas preconceituosas irão discriminar" (MODESTO; MINELLI; FERNANDES; RODRIGUES; BUFOLO; BITENCOURT; PILATI, 2017, p. 2) e, isso, explica o porquê da persistência da discriminação nos ambientes universitários.

Além das pesquisas empíricas acima citadas, gestores de diversas universidades também vem percebendo a persistência de inclinações psicológicas contra os estudantes cotistas. Essa percepção, por exemplo, tiveram os professores Paulo Roberto Cardoso da Silveira e Marta Íris Messias da Silveira (SILVEIRA; SILVEIRA, 2012, p. 231-233) da Universidade Federal de Santa Maria (UFSM). Para eles, a indiferença 
e o silêncio das maiorias denotam o racismo institucionalizado contra as minorias. Acrescentam ainda que, a adoção de cotas, por ser medida emergencial e imediatista, não resolvem os conflitos sociais e raciais que continuam ocultos no ambiente acadêmico. Ademais, nas suas concepções, a imobilização dos diversos setores da universidade com programas efetivos que garantam a permanência dos ingressantes pelo sistema de cotas, permite que a comunidade acadêmica apenas alivie sua consciência em relação ao seu papel no combate à desigualdade racial, mas não alteram as práticas, posturas e vontades políticas historicamente instituídas.

Constatação diversa, mas não menos viciosa, teve a professora Maria José de Jesus Alves Cordeiro (2012, p. 37-8) em relação às cotas para negros e indígenas na Universidade Estadual do Mato Grosso do Sul (UEMS). No caso da referida universidade, o problema verificado inicialmente foi o afastamento dos índios da universidade e posteriormente o não preenchimento das vagas indígenas nos vestibulares subsequentes. Segundo a professora, esse fato deve ser imputado à discriminação contra os estudantes cotistas (indígenas) - perpetrados por alunos não cotistas e professores desconhecedores da realidade indígena - pela dificuldade de adaptação à cultura, à linguagem, às normas e aos valores dos grupos dominantes que ainda são utilizados como currículo oficial nos bancos escolares.

Apenas para citar mais um exemplo, na Universidade Federal de Goiás (UFG) também se percebeu a dificuldade na absorção da ideia da reserva de vagas para estudantes negros de escola pública. A percepção foi dos professores Diogo Marçal Cerqueira, Carlianne Paiva Gonçalves e Alex Ratts (2012, p. 283), a partir das declarações de representantes da universidade sobre o programa UFGInclui. Segundo análise dos referidos professores, constantemente se nota nessas declarações, alternativas justificadoras para o sistema de cotas, como, a necessidade de melhoria no ensino público básico para melhor beneficiar os estudantes negros e a desnecessidade do programa para a maioria dos cotistas, uma vez que muitos deles obtiveram e obtém notas suficientes para ser aprovados pelo sistema universal ${ }^{11}$.

Essa postura preconceituosa justificada dos próprios gestores das universidades públicas gera um receio de discutirem as cotas de 
estudantes negros de escola pública, tanto no interior da universidade quanto publicamente. As "cotas envergonhadas", como chamam, "não proporcionam a construção de um cenário de discussões francas e abertas sobre as ações afirmativas na UFG e levam consequentemente os/as cotistas a se esconderem" (CERQUEIRA; GONÇALVES; RATTS, 2012, p. 283). A consequência disso é que os cotistas deixam de usufruir o que a universidade poderia lhes proporcionar como política de permanência, exatamente por não exercerem o direito.

A situação que se verifica na Universidade Federal de Goiás (UFG), portanto, é a mesma exposta na pesquisa da professora Maria Cristina Figueiredo Aguiar Guasti, ou seja, a ocultação dos alunos cotistas por constrangimentos. Esse constrangimento impede que esses estudantes sejam reconhecidos para se sentirem pertencidos ao grupo. Isso demonstra inequivocamente a presença do racismo e de outros vícios que impedem (como obstáculo) o desenvolvimento humano.

Evidenciadas a presença de externalidades negativas com a chegada dos cotistas nas universidades públicas, o próximo tópico destina-se a apresentar a hipótese para a persistência dos vícios no ambiente universitário, bem como a discutir se tais vícios (externalidades negativas) influenciam, direta e negativamente, a justiça das políticas públicas de cotas.

\section{A HIPÓTESE PARA A PERSISTÊNCIA DOS VÍCIOS NOS AMBIENTES UNIVERSITÁRIOS E A MISSÃO DAS UNIVERSIDADES PARA A SUPERAÇÃO DAS INJUSTIÇAS SOCIAIS}

Este tópico se encarregará de justificar a persistência dos vícios (preconceitos, racismos, intolerâncias e discriminações) nos ambientes universitários com a chegada dos cotistas e, assim o fará, buscando utilizar como base os elementos da própria teoria liberal igualitária sobre justiça.

A hipótese para a persistência de vícios nas relações entre cotistas e não cotistas é porque, possivelmente, as pessoas encararam e ainda encaram as regras sobre política de reserva de vagas como injustas. A injustiça dessas ações afirmativas podem decorrer de dois fatores 
alternativos: (a) ainda não se formou um consenso sobreposto sobre a política de distribuição de direitos (vagas nas universidades) ou, de outro modo, (b) a política de cotas escolhida não está de acordo com a prescrição contida na fórmula ${ }^{12}$, uma vez que o valor ligado à justiça para a referida ação governamental seria diferente do valor difundido no meio social (HELLER; FÉHER, 2002, p. 121).

A segunda hipótese está descartada, haja vista que o presente trabalho parte da premissa de que as políticas de cotas educacionais passaram pelo crivo da justiça constante do consenso constitucional, o qual permite variadas leituras, especialmente, a liberal igualitária, conforme se verifica por todos os fundamentos expostos no primeiro tópico. Logo, a referida ação governamental não é injusta, pois o valor por ela consagrado obedece às mais aceitas teorias da justiça.

Desse modo, a principal hipótese que justifica a dificuldade para a incorporação e aceitação da política de cotas educacionais e dos cotistas pelos grupos majoritários (não cotistas), é porque os valores compartilhados pela sociedade ainda não atingiram um consenso sobreposto, embora, o consenso constitucional já tenha sido alcançado por meio das garantias constitucionais asseguradas pela CRFB de 1988 e, a partir do qual os legisladores constituídos deram a conformação pertinente.

De fato, a sociedade brasileira ainda é uma sociedade meritocrática, ou seja, que valoriza a dedicação e o esforço e não a igualdade. Por essa razão, aos olhos da população, ainda subsiste como critério justo de admissão às faculdades o critério da capacidade do estudante. Isso, certamente dificulta a compreensão da justiça acerca das políticas sociais e distributivas, fazendo persistir os vícios nas relações entre cotistas e não cotistas, especialmente sob o argumento de violação ao princípio da igualdade.

Entretanto, o fato de a sociedade compartilhar valores como a dedicação e o esforço e não a igualdade, não significa que as políticas sociais e distributivas sejam injustas, como, aliás, já se expôs ao longo de todo primeiro tópico. É que, como explica Michael Sandel (2012, p. 200), da mesma forma como talentos e aptidões naturais não são moralmente justas, as qualidades que uma sociedade valoriza em determinado momento também podem ser moralmente arbitrárias (e, portanto, injustas), como o é a meritocracia exclusivamente. 
Em síntese, a conexão que se pode fazer entre vícios e virtudes é que: na sociedade em que a igualdade é um valor, a discriminação positiva deve ser um mecanismo de ação afirmativa adotável com vistas a sanar problemas sociais. Por outro lado, a sociedade em que a meritocracia (dedicação e esforço) é um valor, a discriminação odiosa pode ser o resultado negativo das políticas públicas de ações afirmativas, precisamente as de reserva de vagas.

A questão, no entanto, é bastante tormentosa e polêmica, pois a aceitação do valor da igualdade atrelado à virtude da justiça ainda demanda maiores discussões. Mesmo filósofos pertencentes a mesma linha de pensamento, podem adotar valores distintos para a justiça. Agnes Heller e Ferenc Feher (2002, p. 180), por exemplo, indicam outros valores que não a igualdade para a justiça. Para eles, os dois valores universalizados e incondicionais da sociedade moderna são a liberdade e a vida. Nesse sentido, entendem que o padrão absoluto pelo qual se pode julgar a justiça ou injustiça de normas e regras deve ser assim formulado: "igual liberdade para todos; iguais oportunidades de vida para todos” (HELLER; FÉHER, 2002, p. 180). Em sentido contrário, afirmam a igualdade como um valor condicional, no sentido de que precisa ser relacionada aos valores de liberdade e vida para dar-lhe sentido, pois "a igualdade na miséria ou na ausência de liberdade, por exemplo, é de valor negativo” (HELLER; FÉHER, 2002, p. 180).

Ademais, a hipótese apresentada - ausência de consenso em relação ao valor da igualdade -, é ainda mais plausível se se partir da premissa de que a própria Constituição brasileira, em interpretação literal, não permite dizer que a política de cotas educacionais seria justa. Explica-se. 0 texto constitucional prevê expressamente o acesso à universidade por meio da capacidade individual ${ }^{13}$ e isso pode provocar dúvidas em relação à justiça da regra, já que o justo decorre do agir conforme a prescrição contida na fórmula (HELLER; FÉHER, 2002, p. 173). A prevalecer essa interpretação, não haveria, no Brasil, sequer consenso constitucional para implantar a ação afirmativa de reserva de vagas.

Como subsídio de contexto, os objetivos da educação superior, no Brasil, são voltados exclusivamente para o mercado de trabalho. Por esse motivo, embora não seja este o intuito do trabalho, é de se questionar os 
valores compartilhados pelo Poder Constituinte em termos de educação superior. Pela análise da Constituição, particularmente na parte destinada ao direito à educação, garantiu-se a obrigatoriedade de acesso apenas à educação básica e fundamental, mas não em relação à educação superior ${ }^{14}$, o que justificam as questões apresentadas neste tópico: a necessidade de seleção para ingresso nas faculdades e a persistência de vícios contra as pessoas que têm acesso por critérios que não sejam o qualitativo.

Em nível constitucional, os dois níveis da educação foram tratados de modos diversos, cada um apresentando nítidas distinções entre suas características e seus objetivos. De imediato, insta destacar que Estado não é obrigado a garantir a presença de todos no ensino superior; ou seja, o Estado não está obrigado com a universalização da educação superior, a não ser no limite da capacidade intelectual individual (MALISKA, 2014, p. 1971), ao contrário do que ocorre com a educação básica (infantil, fundamental e médio). Isso quer dizer que, todas as pessoas, de zero a dezoito anos são obrigadas a ser matriculadas e a frequentar a educação básica, ao passo que, nem todos são obrigados pelo Estado a ter formação universitária, mas se o fizer, compete ao Poder Público garantir este desiderato ao cidadão.

Por outro lado, o objetivo da educação superior é diferente da educação básica, destinando-se a formar quadros profissionais qualificados para o país, de níveis internacionais, e, dessa forma, a aferição da capacidade individual seria indiscutível e necessária, sob pena de um comprometimento inquestionável do nível de formação universitário (MALISKA, 2014, p. 1971), daí porque se justifica a adoção dos processos de seleção vestibular por mérito qualitativo.

Os objetivos da educação básica, por conseguinte, estão no art. 205 da Constituição da República e são (a) promover o pleno desenvolvimento da pessoa, (b) promover o preparo para o exercício da cidadania e (c) promover a qualificação para o trabalho. Já a educação superior tem como objetivo formar quadros profissionais qualificados para o país, como se conclui pela leitura do art. 208, V da CRFB de 1988.

Como se vê, uma interpretação literal do texto constitucional poderia levar a aparente ideia de que as políticas públicas de cotas não seriam justas e adotá-las implicaria em violação ao princípio da igualdade. 
Essa interpretação, contudo, é suficiente para incutir no senso comum dos cidadãos a permanência do critério meritocrático, provocando, por consequência, os vícios nas relações entre cotistas e não cotistas.

A persistência dos vícios com a chegada dos cotistas nas universidades se deve também à omissão das próprias universidades públicas, a quem incumbem promover o acolhimento dos estudantes cotistas, mediante ações de inclusão étnico-racial e social-econômica. Em complemento ao disposto no consenso constitucional, bem como aos valores compartilhados pela comunidade, as universidades públicas deveriam incorporar como missão ${ }^{15}$ tais desideratos, como fim da ação governamental.

Evidentemente, a missão de uma universidade não seria definida livremente, mas de acordo com as instituições sociais que figuram mais frequentemente nos debates sobre justiça (escolas, universidades, ocupações, profissões, órgãos públicos) (SANDEL, 2012, p. 222). Dessa forma, uma vez que a universidade defina sua missão e estabeleça seus padrões de admissão, por exemplo, por critérios de beneficiamento a grupos minoritários (pobres, não brancos, indígenas etc.), uma pessoa tem o direito à legítima expectativa de ser admitida na medida em que preencha esses padrões melhor do que outros candidatos (SANDEL, 2012, p. 216). Assim, seja por cotas ou por méritos, a justiça da seleção depende dos critérios previamente definidos pela missão das universidades.

Particularmente, no Brasil, o que se verifica é uma implementação incompleta da política de cotas. Embora, por vezes, as políticas de cotas sejam divulgadas por legisladores, administradores, gestores de universidades e até mesmo por doutrinadores, com os objetivos de propiciar simultaneamente o acesso e a permanência dos estudantes nas universidades públicas, na prática, não é exatamente isso o que se verifica. A começar pela Lei n. $12.711 / 2012^{16}$ que instituiu a política de cotas nas universidades públicas federais e nas instituições de ensino técnico de nível médio, que se preocupou apenas com o ingresso de estudantes não brancos e de baixa renda, não dispondo qualquer ação afirmativa em relação à permanência dos cotistas.

As políticas de permanência são de incumbência das universidades que recebem os estudantes cotistas, especialmente em relação a programas de inclusão e adaptação social, com o fim de proporcionar o reconhecimento 
e a sensação de pertencimento dos cotistas ao grupo e, em contrapartida, evitar inclinações psicológicas por parte dos não cotistas.

Pouquíssimas universidades no Brasil trazem como missão a promoção da diversidade e a inclusão social dos grupos minoritários (baixas rendas, não brancos, indígenas e deficientes físicos), como ocorreu na Universidade do Texas, no caso Cheryl Hopwood. Para se ter uma ideia, dentre as universidades públicas do Estado do Paraná (Curitiba ${ }^{17}$, Maringá ${ }^{18}$, Ponta Grossa ${ }^{19}$, Jacarezinho ${ }^{20}$ e Cascavel $^{21}$ ), apenas a Universidade Estadual de Londrina (UEL) ${ }^{22}$ apresenta como missão a igualdade de condições de acesso e permanência aos estudantes, denotando, assim, um arranjo institucional completo à adoção do sistema de cotas, mediante a promoção da diversidade e da inclusão social. As demais universidades paranaenses primam apenas pela produção de conhecimento e saber científico, por meio da pesquisa docente e discente, com vistas ao desenvolvimento sócio-econômico e regional, o que, de certo modo, contribui para a persistência dos vícios nos ambientes universitários, na medida em que privilegia, única e exclusivamente, a capacidade intelectual e o desempenho do estudante.

Dessa forma, embora tenha se garantido o acesso dos estudantes às universidades públicas, rompendo as barreiras sócio-econômicas e étnico-raciais, os ambientes universitários ainda não estão em completa conformidade para receber os estudantes de grupos minoritários. Para tanto, necessário se faz alterar a missão, visão e valores das referidas instituições, o que pode ser feito por meio da adoção de uma política de Compliance $^{23}$ nas universidades públicas.

A proposta merece ser objeto de outro estudo mais aprofundado, bem como de outro processo de política pública de reserva de vagas, não tendo o presente artigo o intuito de descortiná-la ou investigá-la. Mas é evidente que a proposta de Compliance para as universidades públicas é salutar e relevante, vislumbrando-se como única alternativa, nesse momento, a permitir a promoção da diversidade e da inclusão social.

A promoção da diversidade e a inclusão social, por sua vez, como uma das missões das universidades públicas implicaria estar em profunda conformidade com os valores constitucionais e as normas e regras infraconstitucionais pertinentes ao ingresso e permanência dos estudantes 
cotistas nos bancos escolares. Ademais, a política de Compliance, por si só, estimularia às universidades públicas a cumprir com a legislação referente ao caso, por meio dos seguintes objetivos: (a) a criação de uma estrutura institucional composta por órgãos, conselhos e colegiados destinados às discussões e debates no âmbito da política de reserva de vagas; (b) a implantação de programas de concessão de bolsas e outros apoios financeiros aos estudantes cotistas por critério sócio-econômico; (c) a elaboração de projetos de extensão visando a divulgar ao público externo à universidade a importância da disseminação do valor constitucional da igualdade como virtude da justiça; (d) a elaboração de programas de inclusão visando a facilitar a adaptação dos novos estudantes (cotistas e não cotistas) e servidores públicos a um ambiente mais plural; (e) o oferecimento de disciplinas voltadas ao intercâmbio cultural com os estudantes cotistas por critério étnico-racial; entre outros.

Enfim, a adoção e implantação de uma política de Compliance nas universidades públicas permitiria conciliar a pesquisa com excelência, fundamental para o desenvolvimento econômico do país, mas também a promoção da diversidade e a inclusão social, fundamental para o desenvolvimento humano, culminando, assim, com o atingimento de todos os valores propostos pela CRFB.

\section{CONCLUSÃo}

As políticas de acesso ou ingresso às universidades públicas por critérios alternativos (social-econômico, étnico-racial e de gênero) de beneficiamento a grupos minoritários passou pelo crivo da justiça, notadamente pela concepção desenvolvida pelos liberais igualitários. Segundo os fundamentos filosóficos apresentados, as políticas de cotas são justas, porque o valor compartilhado pela sociedade e trazido como consenso constitucional pelo Poder Constituinte foi a igualdade. Esta, por sua vez, autorizou a elaboração da Lei n. 12.711/2012 pelas instâncias administrativa e legislativa, bem como orientou o julgamento da constitucionalidade da ação governamental de reserva de vagas na 
Arguição de Descumprimento de Preceito Fundamental n. 186 e no Recurso Extraordinário (em Mandado de Segurança) n. 597.285/RS.

Tendo em vista que as políticas de cotas educacionais têm por fundamento a justiça distributiva e visam ao combate das desigualdades entre as pessoas, as reações adversas aos grupos minoritários beneficiados são intuitivamente previsíveis e empiricamente demonstráveis. Assim, as pesquisas citadas ao longo do trabalho, comprovaram a persistência do preconceito, do racismo, da intolerância e da discriminação nos ambientes universitários com a chegada dos cotistas aos bancos escolares.

A hipótese para a persistência desses vícios nas relações entre cotistas e não cotistas se funda no fato de que indivíduos ainda percebem as regras sobre política de reserva de vagas como injustas. 0 senso de injustiça dessas ações afirmativas decorre do fato de que o consenso sobre a política de distribuição de direitos, especificamente de vagas nas universidades ainda não se formou como valor compartilhado pela sociedade que, por sua vez, ainda valoriza exclusivamente a dedicação e o esforço, enfim, a meritocracia.

Embora já tenha se garantido o ingresso dos estudantes às universidades públicas, rompendo as barreiras sócio-econômicas e étnico-raciais, as próprias instituições de ensino superior ainda não se adequaram integralmente em missão, visão e valores (Compliance) à política pública de reserva de vagas, tornando-a ineficaz e impedindo a realização completa da justiça distributiva. Isso se observa uma vez que a mera garantia de acesso, sem a garantia de permanência e continuidade, não é suficiente para atingir a finalidade que se espera das políticas de cotas educacionais.

Para tanto, necessário se faz alterar a missão, visão e valores, mediante uma política de Compliance para as instituições públicas de ensino, que ainda não estão em conformidade com os valores constitucionais e as normas e regras infraconstitucionais pertinentes ao ingresso e permanência dos estudantes cotistas nos bancos escolares. Estar em conformidade é fundamental para que as universidades públicas possam conciliar a pesquisa com excelência e a promoção da diversidade e a inclusão social, permitindo, assim, o pleno desenvolvimento humano, social e econômico. 


\section{NOTAS}

1 O critério étnico-racial visa a correção do problema da exclusão social dos não brancos, especialmente, negros e indígenas, tendo dois objetivos precípuos: (a) corrigir os erros do passado; e, (b) promover a diversidade étnico-racial. 0 primeiro objetivo funda-se na teoria da justiça compensatória e procura reparar os afrodescendentes e indígenas atuais pelos danos da escravidão cometidos contra seus antepassados. 0 segundo objetivo, por sua vez, teria o intuito de proporcionar o desenvolvimento da cidadania em todos os discentes, permitindo o intercâmbio de conhecimentos, experiências, vivências, valores éticos, morais e culturais.

20 critério social-econômico visa a correção do fenômeno da trajetória inversa dos alunos. Explica-se. Tendo em vista que o acesso ao ensino superior no Brasil, notadamente, ao universitário público, se dá mediante a capacidade individual de cada um, estudantes de baixa renda e oriundos de escolas públicas teriam dificuldade de acesso e permanência nas universidades públicas, por problemas socioeconômicos. Essa dificuldade seria decorrente de dois fatores: (a) o primeiro, em razão da educação de má qualidade oferecida aos estudantes de baixa renda nas escolas públicas. Assim, sem condições de competir no processo seletivo, esses estudantes acabam por fazer um caminho inverso na educação, ou seja, acabam tendo que ingressar em faculdade privada, enquanto que os estudantes do ensino privado acabam ingressando em universidade pública; $\mathrm{e}$ (b) o segundo, em virtude da baixa oferta de vagas no ensino superior público em comparação com a oferta de vagas nas faculdades privadas, o que obrigaria as famílias a matricularem seus filhos em faculdades particulares.

3 Por meio da autonomia universitária, a Universidade Estadual da Bahia, a partir do ano de 2019, oferecerá cotas de vagas para as referidas pessoas.

4 A expressão "vícios" é aqui utilizada em sentido oposto a "virtudes". Para John Rawls, em sua teoria sobre a justiça, ambas estão relacionadas com a justiça e a injustiça. Para o filósofo, as virtudes morais são traços de caráter de bases amplas que é racional que as pessoas queiram encontrar umas nas outras quando associadas. Os vícios, por outro lado, são traços de bases amplas que não são desejados. Evidentemente, continua o filósofo, as partes preferirão concepções de justiça cuja realização institucional não gere tais propensões (2002, p. 658).

5 Não há, portanto, uma ideia de justiça ou uma justiça ideal. A justiça pode receber várias leituras e, nesse sentido, também, entende Agnes Héller e Ferenc Feher: "as normas e regras de um aglomerado podem ser elas próprias informadas e orientadas por várias ideias de justiça" (2002, p. 177).

6 Outros doutrinadores, especialmente, constitucionalistas também adotam essa concepção de justiça, muito embora, reportem aos princípios da justiça como direitos naturais. Assim, é a posição de Daniel Sarmento e Cláudio Pereira Souza Neto: "o constitucionalismo liberal brasileiro positivou aquilo que é compartilhado pela sociedade, ou seja, os direitos naturais: liberdades básicas, igualdade formal, segurança e propriedade. Assim, a antiga primazia do direito natural sobre o direito positivo foi substituída pela correspondente superioridade das normas constitucionais sobre as infraconstitucionais" (2017, p. 23-4).

7 Agnes Heller e Ferenc Feher comungam da mesma filosofia, para quem, "só se pode atribuir justiça ou injustiça a uma ação executada segundo regras e normas; a natureza não pode ser justa ou injusta; os sentimentos em si não podem ser chamados de justos ou injustos" (2002, p. 174).

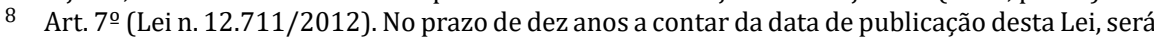
promovida a revisão do programa especial para o acesso às instituições de educação superior de estudantes pretos, pardos e indígenas e de pessoas com deficiência, bem como daqueles que tenham cursado integralmente o ensino médio em escolas públicas.

9 Nesses quesitos, pesquisas realizadas até o momento na Universidade de São Paulo (Cf. MATOS; PIMENTA; ALMEIDA; OLIVEIRA, 2012, p. 720-742) e na Universidade Federal do Paraná (Cf. MALISKA, 2014, p. 1964-1975) demonstram que as propostas iniciais atingiram, a contento, suas metas, corrigindo o problema da chamada trajetória inversa dos alunos e permitindo que estudantes de baixa renda tenham acesso aos cursos de elite. Ademais, as pesquisas também comprovaram que não houve substancial comprometimento da qualidade do ensino e dos 
estudantes, não afetando o desempenho acadêmico e nem mesmo a qualidade do conjunto de estudantes selecionados.

10 O método tradicional de pesquisa existente é por medidas explícitas ou diretas ou de auto-relato. Entretanto, a adoção de tais métodos indicavam baixos índices de preconceito e discriminação, haja vista que seus entrevistados não revelavam a sua verdadeira desejabilidade social, diante da presença de normas sociais igualitárias. Ou seja, a pessoa pode ser preconceituosa, mas deixar o seu posicionamento encoberto ao participar de pesquisas que administrem medidas explícitas sobre preconceito (MODESTO; MINELLI; FERNANDES; RODRIGUES; BUFOLO; BITENCOURT; PILATI, 2017, p. 2).

11 Essas declarações, também, são formas de preconceitos que podem acarretar a discriminação. A situação é a mesma evidenciada pela pesquisa realizada pelo "modelo de discriminação justificada" acima mencionada.

12 Agnes Heller e Ferenc Feher consideram uma situação injusta, quando não se age de acordo com a prescrição contida na fórmula, logo, "só se pode atribuir justiça ou injustiça a uma ação executada segundo regras e normas". E a injustiça se verifica quando: (a) aplica-se normas e regras inconsistentemente; (b) aplica-se de modo descontínuo; (c) aplica-se uma norma ou regra diferente daquela que o aglomerado humano constitui para seus membros (2002, p. 173).

13 Art. 208, V (Constituição da República). 0 dever do Estado com a educação será efetivado mediante a garantia de: acesso aos níveis mais elevados do ensino, da pesquisa e da criação artística, segundo a capacidade de cada um.

14 O Sistema Educacional Brasileiro é constituído por dois níveis [art. 21 da Lei n. 9.394/1996 (Lei de Diretrizes e Bases da Educação)]: (a) Educação básica; e, (b) Educação superior. 0 primeiro nível, por sua vez, é composto por três etapas: (a) educação infantil (crianças de até 6 (seis) anos de idade); (b) ensino fundamental (crianças e adolescentes dos 7 (sete) até os 15 (quinze) anos); e, (c) ensino médio (adolescentes de 16 (dezesseis) a 18 (dezoito) anos).

15 A Universidade do Texas, ao negar a vaga para a estudante Cheryl Hopwood para privilegiar estudantes negros, demonstrou que possuía um propósito cívico e uma missão, qual seja, "ajudar a aumentar a diversidade da carreira advocatícia no Texas e permitir que negros e hispânicos ocupassem posições de liderança no governo e no sistema judiciário em geral" (SANDEL, 2012, p. 213).

16 Basta ler sua ementa: "Dispõe sobre o ingresso nas universidades federais e nas instituições de ensino técnico de nível médio e dá outras providências".

17 A missão da Universidade Federal do Paraná (UFPR) é: "fomentar, construir e disseminar o conhecimento, contribuindo para a formação do cidadão e desenvolvimento humano sustentável".

18 A missão da Universidade Estadual de Maringá (UEM) é: "produzir conhecimento por meio da pesquisa; organizar, articular e disseminar os saberes por meio do ensino e da extensão, para formar cidadãos, profissionais e lideranças para a sociedade".

19 A missão da Universidade Estadual de Ponta Grossa (UEPG) é: "produzir e difundir conhecimentos múltiplos, no âmbito da graduação e da pós-graduação, visando à formação de indivíduos éticos, críticos e criativos, para a melhoria da qualidade de vida humana".

20 A missão da Universidade Estadual do Norte do Paraná (UENP) é: "atuar na produção do conhecimento científico em suas mais diversas formas e no processo de desenvolvimento regional e do Estado do Paraná, participando ativamente no trabalho de construção integral da sociedade e de seus cidadãos, buscando sempre a melhoria da qualidade de vida, promovendo a democracia, a cidadania e o desenvolvimento sócio-econômico, pela valorização e socialização do conhecimento e do saber historicamente construído e constituído".

21 A missão da Universidade Estadual do Oeste do Paraná (Unioeste) é: "produzir, sistematizar e socializar o conhecimento, contribuindo com o desenvolvimento humano, científico, tecnológico e regional, comprometendo-se com a justiça, a democracia, a cidadania e a responsabilidade social".

22 A missão da Universidade Estadual de Londrina (UEL) é: "a gestão democrática com plena autonomia didático-científica, comprometida com o desenvolvimento e a transformação social, econômica, política e cultural do Estado do Paraná e do Brasil. Busca garantir a indissociabilidade entre ensino, pesquisa e extensão, a igualdade de condições de acesso e de permanência discente, a liberdade e respeito ao pluralismo de ideias, tendo como finalidade a produção e disseminação 
do conhecimento, formando cidadãos e profissionais com competência técnica e humanística, orientada por valores éticos de liberdade, igualdade e justiça social".

23 Com base em Marcia Carla Pereira Ribeiro e Patrícia Dittrich Ferreira Diniz, no Brasil, a política de Compliance surgiu a partir da Lei Anticorrupção Empresarial (Lei n. 12.846/2013), com vistas à responsabilização administrativa e civil das pessoas jurídicas pela prática de atos contra a Administração Pública. Embora tivesse como destinatário, inicialmente, as empresas, a política de Compliance pode ser aplicável a todos os tipos de organizações, inclusive, à própria Administração Pública, estando relacionada a questões estratégicas. Compliance é uma expressão que se volta para as ferramentas de concretização da missão, da visão e dos valores de uma organização ou instituição pública. A política de Compliance não se limita apenas ao mero cumprimento de regras formais e informais, sendo o seu alcance bem mais amplo, ou seja, é um conjunto de regras, padrões, procedimentos éticos e legais, que, uma vez definido e implantado, passa a ser a linha mestra que orientará o comportamento da organização ou instituição pública no ambiente em que atua, bem como a atitude os seus funcionários ou servidores (2015, p. 87-8).

\section{REFERÊNCIAS}

CASTRO, Jorge Abrahão de. Política social no Brasil: marco conceitual e análise da ampliação do escopo, escala e gasto público. Revista Brasileira de Monitoramento e Avaliação, Porto Alegre, n. 1, p. 66-95, jan./jun. 2011.

CERQUEIRA, Diogo Marçal; GONÇALVES, Carlianne Paiva; RATTS, Alex. As marcas da travessia: o processo de implementação de ações afirmativas e cotas na Universidade Federal de Goiás. In: SANTOS, Jocélio Teles dos (org.). Cotas nas Universidades: análise dos processos de decisão. Salvador: CEAO, 2012, p. 259-284.

CITTADINO, Gisele. Pluralismo, Direito e Justiça Distributiva: Elementos da Filosofia Constitucional Contemporânea. Rio de Janeiro: Lumen Juris, 1999.

CLÈVE, Clèmerson Merlin. Ações afirmativas, justiça e igualdade. Doutrinas Essenciais e Direito Constitucional, São Paulo, v. 8, ago./2015, p. 671-695.

CORDEIRO, Maria José de Jesus Alves. Cotas para negros e indígenas na Universidade Estadual de Mato Grosso do Sul. In: SANTOS, Jocélio Teles dos (org.). Cotas nas Universidades: análise dos processos de decisão. Salvador: CEAO, 2012, p. 17-38.

FREY, Klaus. Políticas Públicas: um debate conceitual e reflexões referentes à prática da análise de políticas públicas no Brasil. Planejamento e Políticas Públicas, Brasília, n. 21, p. 211-259, jun./2000. 
GARGARELA, Roberto. As teorias da justiça depois de Rawls: um breve manual de filosofia política. Tradução de Reis Freire. São Paulo: Martins Fontes, 2008.

GUASTI, Maria Cristina Figueiredo Aguiar. Representações sociais: sobre as ações afirmativas no ensino superior e sobre os estudantes cotistas na Ufes. Curitiba: CRV, 2016.

HELLER, Agnes; FEHÉR, Ferenc. A condição política pós-moderna. Tradução de Marcos Santarrita. 2. ed., Rio de Janeiro: Civilização Brasileira, 2002.

JENSEN, Geziela. Política de cotas raciais em universidades brasileiras: entre a legitimidade e a eficácia. 2. ed. Curitiba: Juruá, 2015.

MACINTYRE, Alasdair. Depois da Virtude. Tradução de Jussara Simões. Bauru: EDUSC, 2001.

MAIA, Gretha Leite; MELO, César. Lei de Cotas no Ensino Público: fundamentos, dispositivos normativos e desafios de implementação. Revista de Direito Administrativo e Infraestrutura, São Paulo, v. 2, jul.-set./2017, p. 165-184.

MALISKA, Marcos Augusto. Art. 208 da Constituição da República. In: CANOTILHO, J. J. Gomes; MENDES, Gilmar Ferreira; SARLET, Ingo Wolfgang; STRECK, Lenio Luiz. Comentários à Constituição do Brasil. São Paulo: Saraiva, 2014, p. 1964-1975.

MARIO, Camila Gonçalves de. Concepções de justiça e a análise de políticas públicas. Administração Pública e Gestão Social. Modalidade Editorial: Eletrônica - http://www.apgs.ufv.br. V. 1, N. 1 (janeiro/março 2016). Viçosa (MG). Departamento de Administração e Contabilidade da Universidade Federal de Viçosa - UFV.

MATOS, Maurício dos Santos; PIMENTA, Selma Garrido; ALMEIDA, Maria Isabel de; OLIVEIRA, Maria Amélia de Campos. 0 impacto do Programa de Inclusão Social da Universidade de São Paulo no acesso de estudantes de escola pública ao ensino superior público gratuito. Revista Brasileira de Estudos Pedagógicos, Brasília, v. 93, n. 235, p. 720-742, set./dez. 2012.

MODESTO, João Gabriel; MINELLI, Ana Caroline; FERNANDES, Maria Paula; RODRIGUES, Matheus; BUFOLO, Ravena; BITENCOURT, Rodolfo; PILATI, Ronaldo. Racismo e políticas afirmativas: evidências do modelo de discriminação 
justificada. Psicologia social, organizacional e do trabalho, Brasília, v. 33, p. 1-8, 2017.

NOVAIS, Jorge Reis. As restrições aos Direitos Fundamentais não expressamente autorizadas pela Constituição. 2. ed. Coimbra: Coimbra Editora, 2010.

RAWLS, John. Justiça como equidade: uma reformulação. Tradução de Cláudia Berliner. São Paulo: Martins Fontes, 2003.

RAWLS, John. Uma teoria da justiça. Tradução de Almiro Pisetta e Lenita Maria Rímoli Esteves. São Paulo: Martins Fontes, 2016.

RIBEIRO, Marcia Carla Pereira; DINIZ, Patricia Dittrich Ferreira. Compliance e Lei Anticorrupção nas empresas. Revista de Informação Legislativa, Brasília, ano 52, n. 205, p. 87-105, jan./mar. 2015.

RODRIGUES, Rui Martinho. RODRIGUES, Carlos Roberto Martins; SILVA, Maria Josefina da; ALBUQUERQUE, Cândido Bittencourt de. A (i)legitimidade das políticas públicas: a República entre a igualdade e a especificidade. São Paulo: Malheiros, 2015.

SANDEL, Michael J. Justiça: o que é fazer a coisa certa. Tradução de Heloísa Matias e Maria Alice Máximo. Rio de Janeiro: Civilização brasileira, 2012.

SILVEIRA, Paulo Roberto Cardoso da; SILVEIRA, Marta Íris C. Messias da. Da maioria silenciosa à minoria mobilizada: as tensões e contradições na implantação das ações afirmativas na Universidade Federal de Santa Maria RS. In: SANTOS, Jocélio Teles dos (org.). Cotas nas Universidades: análise dos processos de decisão. Salvador: CEAO, 2012, p. 209-234.

SOUSA, Virgínio Motta. As ações afirmativas nas universidades brasileiras e o conceito de justiça na obra de Ronald Dworkin. In: BRANCO, Paulo Gonet; BARROS, Janete Ricken de. Dignidade da pessoa humana e igualdade: aspectos pontuais. Brasília: IDP, 2014, p. 57.

SOUZA NETO, Cláudio Pereira; SARMENTO, Daniel. Direito Constitucional: teoria, história e métodos de trabalho. 2. ed. Belo Horizonte: Fórum, 2017.

Recebido em: 19-01-2019

Aprovado em: 26-10-2020 


\section{Edson Mitsuo Tiujo}

Mestrado em Direito Negocial pela Universidade Estadual de Londrina (2006). Graduação em Direito pela Universidade Estadual de Maringá (2003). Professor titular da Universidade Estadual de Maringá. Tem experiência na área de Direito, com ênfase em Direito Civil, atuando principalmente nos seguintes temas: direito de família, direito constitucional, direito civil, união estável e responsabilidade. E-mail: edsonmitsuo@yahoo.com.br

\section{Bruno Grego dos Santos}

Doutor em Direito do Estado pela Faculdade de Direito da Universidade de São Paulo (USP) com estágio de pesquisa de doutoramento na Faculdade de Direito da Universidade de Coimbra (FDUC) e intercâmbio acadêmico na University of Notre Dame Australia (UNDA). É Advogado, Professor da Escola de Direito da Pontifícia Universidade Católica do Paraná (PUCPR), Vice-Presidente da OAB Maringá, National Coordinator da Global Pandemic Network, Expert Consultant do Round Table Group e Professor do Instituto Brasiliense de Direito Público (IDP). Foi Consultor da ONU no Programa das Nações Unidas para Cidades (UNHabitat). Professor Visitante nos cursos de Mestrado e Doutorado em Direito da USP, Delegado na III Conferência das Nações Unidas sobre Habitação e Desenvolvimento Urbano Sustentável (Habitat-III). Professor Visitante na University of Notre Dame Australia e Procurador Municipal, tendo realizado intercâmbio profissional na Procuradoria-Geral do Estado de Western Australia, na Francis Burt Chambers, Butcher Paull \& Calder e outras grandes bancas internacionais. É membro do Centro de Estudos em Direito Administrativo e Urbanístico da USP (CEDAU), membro do Grupo de Discussão Comparative Administrative Law Initiative da Yale Law School, membro da International Society of Public Law da New York University, membro acadêmico da Procurement Law Academic Network, Diretor Jurídico da Software by Maringá e membro do Instituto Brasileiro de Advocacia Pública. Venceu o VII Prêmio Innovare na categoria Advocacia, a Láurea Acadêmica da Universidade Estadual de Maringá e a menção honrosa do II Prêmio Francisco Cunha Pereira Filho. Recebeu, em 2020, Menção Honrosa e Voto de Congratulações da Assembleia Legislativa do Estado do Paraná, "pelos brilhantes e relevantes serviços prestados na área jurídica em nosso Estado". E-mail: bruno@gregosantos.com.br

Universidade Estadual de Maringá, Centro de Estudos Sócio-Econômicos, Departamento de Direito Privado e Processual.

Universidade Estadual de Maringá - Zona 7

87020900 - Maringá, PR - Brasil 
